\title{
SISTEM INFORMASI PEMASARAN TENAGA KERJA INDONESIA BERBASIS WEB PADA PT. LAATANSA LINTAS INTERNASIONAL
}

\author{
Wiwiek Nurkomala Dewi ${ }^{1}$, Agus Sevtiana ${ }^{2}$, Isep Saefullah ${ }^{3}$ \\ Universitas Catur Insan Cendekia \\ J1.Kesambi 202, Kota Cirebon, Jawa Barat. Telp (0231)220350 \\ Email : wiwiek.nurkomala.dewi@cic.ac.id ${ }^{1}$, a.sevtiana@gmail.com ${ }^{2}$, isepsaefullah04@gmail.com ${ }^{3}$
}

\begin{abstract}
Abstrak
Pencanangan program Masyarakat Ekonomi Asia (MEA) menjadikan semakin lebar pintu gerbang untuk Tenaga Kerja Indonesia bekerja di luar negeri. PT. Laatansa Lintas Internasional sebagai salah satu perusahaan penyalur jasa Tenaga Kerja Indonesia harus memanfaatkan kemajuan teknologi ini dengan menerapkan penggunaan aplikasi yang mampu meningkatkan pelayanan yang ada pada perusahaan. Salah satu cara yang digunakan untuk meraih hal tersebut adalah dengan membuat sebuah "Sistem Informasi Pemasaran Tenaga Kerja Indonesia". Analisa proses bisnis yang terjadi digambarkan dengan menggunakan flow map. Perancangan sistem dibuat menggunakan tools DFD berdasarkan data yang telah diperoleh. Aplikasi ini dibuat menggunakan Bahasa pemrograman PHP dengan memakai basis data MySQL. Sistem Informasi Pemasaran Tenaga Kerja Indonesia mampu mempermudah proses pendataan dan pengarsipan tenaga Kerja Indonesia. Dengan adanya aplikasi ini bagian marketing dapat bekerja lebih efektip dan efisien dalam memasarkan Tenaga Kerja Indonesia ke luar negeri. Pencarian data pada bagian legalisasi dokumen menjadi lebih mudah dan cepat. Data Tenaga Kerja Indonesia yang sudah dimasukan dapat menjadi database Tenaga Kerja Indonesia untuk wilayah cakupan PT. Laatansa Lintas Internasional yaitu wilayah CIAYUMAJAKUNING ( Cirebon, Indramayu, Majalengka dan Kuningan ) serta Lampung.
\end{abstract}

Kata kunci : Tenaga kerja Indonesia, Sistem Informasi, Pemasaran, berbasis web, PT LLI

\begin{abstract}
With the launching of the Asian Economic Community (AEC) program, the gateway for Indonesian Workers working abroad has become wider.PT. Laatansa Lintas Internasional as one of the Indonesian Manpower distribution services companies must take advantage of this technological progress by implementing the use of applications that are able to improve the services available to the company. One way to achieve this is to create an "Indonesian Workers Marketing Information System". Business flow in market information drawed in flow map. The design of system was created using Data Flow Diagram (DFD). This application was created using the PHP programming language and using MySQL as database.The Indonesian Worker Marketing Information System is able to simplify the data collection and archiving process of Indonesian Workers. With this application the marketing department can work more effectively and efficiently in marketing Indonesian Workers abroad. Searching for data in the document legalization section is easier and faster. Indonesian Workers Data that has been entered can be a database of Indonesian Workers for the coverage area of PT. Laatansa Lintas Internasional, namely the CIAYUMAJAKUNING region (Cirebon, Indramayu, Majalengka and Kuningan) and Lampung.
\end{abstract}

Keywords : Indonesian Workers, Marketing, Information Systems, Web based, PT LLI

JURNAL DIGIT Vol. 10, No.1 Mei 2020 : 83 91 


\section{PENDAHULUAN}

\subsection{Latar Belakang}

PT. Laatansa Lintas Internasional adalah sebuah Perusahaan Penyalur Jasa Tenaga kerja Indonesia (PJTKI) bertempat di Jalan Werkudoro Lodan Rukan No. 9 Bima Indah RT. 003 / RW. 06, Desa Tuk Kecamatan Kedawung Kabupaten Cirebon. Negara yang menjadi tujuan penempatan Tenaga Kerja Indonesia (TKI) di PT. Laatansa Lintas Internasional diantaranya Singapura, Malaysia, Hong Kong dan Taiwan. Alur proses penempatan Tenaga Kerja Indonesia di PT. Laatansa Lintas Internasional adalah Calon Tenaga Kerja Indonesia datang mendaftar ke PT. Laatansa Lintas Internasional dengan membawa persyaratan lengkap seperti Kartu Keluarga (KK), Kartu Tanda Penduduk (KTP), Surat Izin Wali dan dokumen lainnya semisal Paspor (untuk yang pernah bekerja di luar negeri). Setelah selesai proses pendaftaran Calon Tenaga Kerja Indonesia melakukan pelatihan bahasa dan keahlian sesuai negara penempatan masing-masing. Ketika keahlian dan kemampuan berbahasa telah mumpuni dilanjutkan dengan proses pemasaran Tenaga Kerja Indonesia oleh Bagian Marketing. Hal-hal yang perlu dilakukan ketika sedang memasarkan Tenaga Kerja Indonesia adalah membuat rekom ID oleh bagian Legalisasi Dokumen agar Tenaga Kerja Indonesia diakui secara resmi oleh pemerintah. Kemudian setelah resmi terdaftar bagi Tenaga Kerja Indonesia yang belum memiliki paspor harus membuat paspor ke Imigrasi. Kemudian ketika paspor sudah ada bagian Marketing akan membuat biodata untuk dikirim ke agensi yang ada di luar negeri agar bisa melanjutkan ke proses interview. Selanjutnya bagi Tenaga Kerja Indonesia yang sudah interview dan mendapatkan majikan pihak marketing akan membuat surat Perjanjian Kerja (PK) antara kedua belah pihak. Bagian Legalisasi Dokumen akan mengajukan visa ketika Tenaga Kerja Indonesia sudah siap untuk berangkat ke negara penempatan. Ketika semua proses sedang berlangsung kadang ada Tenaga Kerja Indonesia yang Mengundurkan diri (MD) dengan sebab alasan yang berbeda-beda. Dan proses terakhir dalam memasarkan Tenaga Kerja Indonesia adalah mendaftar asuransi dan melakukan Pembekalan Akhir Pemberangkatan (PAP).

\subsection{Identifikasi Masalah}

Berdasarkan uraian latar belakang masalah tersebut, penulis membuat identifikasi masalah sebagai berikut :

1. Belum adanya pengarsipan data Tenaga Kerja Indonesia secara digital sehingga kadang membuat proses menjadi lambat.

2. Belum adanya aplikasi yang dapat digunakan bagian marketing untuk mempermudah proses dalam memasarkan Tenaga Kerja Indonesia.

3. Belum adanya aplikasi yang dapat digunakan bagian legalisasi dokumen untuk membantu dalam penyimpanan data proses yang telah dilakukan oleh Tenaga Kerja Indonesia

4. Bagaimana cara merancang dan membangun Sistem Informasi Pemasaran Tenaga Kerja Indonesia pada PT. Laatansa Lintas Internasional?

5. Belum ada aplikasi yang mengefektifkan proses pendataan Tenaga Kerja Indonesia oleh instruktur untuk keperluan bagian marketing.

\subsection{Tujuan Penelitian}

Tujuan dari pembuatan aplikasi ini sebagai berikut :

1. Membuat Sistem Informasi Pemasaran Tenaga Kerja Indonesia yang bisa dipakai oleh karyawan PT. Laatansa Lintas Internasional.

2. Mempermudah Bagian Marketing dalam proses pemasaran Tenaga Kerja Indonesia.

3. Mempermudah bagian Legalisasi Dokumen dalam memproses dokumen Tenaga Kerja Indonesia.

4. Memberikan kecepatan pencarian data Tenaga Kerja Indonesia melalui aplikasi yang dirancang.

5. Meningkatkan pelayanan yang ada pada PT. Laatansa Lintas Internasional.

\section{KAJIAN PUSTAKA}

\subsection{Definisi Sistem Informasi}

Sistem Informasi adalah suatu sistem yang terdiri dari pengumpulan, pemasukan, pemrosesan data, penyimpanan, pengumpulan, pemasukan, pemrosesan data, penyimpanan, pengolahan, pengendalian dan pelaporan sehingga tercapai sebuah informasi yang mendukung pengambilan keputusan di dalam suatu organisasi untuk dapat mencapai sasaran dan tujuannya. 


\subsection{Definisi Pemasaran}

Pemasaran merupakan usaha terpadu untuk menggabungkan rencana-rencana strategis yang diarahkan kepada usaha pemuas kebutuhan dan keinginan konsumen untuk memperoleh keuntungan yang diharapkan melalui proses pertukaran atau transaksi. Kegiatan pemasaran perusahaan harus dapat memberikan kepuasan kepada konsumen bila ingin mendapatkan tanggapan yang baik dari konsumen. Perusahaan harus secara penuh tanggung jawab tentang kepuasan produk yang ditawarkan tersebut. Dengan demikian, maka segala aktivitas perusahaan, harusnya diarahkan untuk dapat memuaskan konsumen yang pada akhirnya bertujuan untuk memperoleh laba.

\subsection{Pengertian Tenaga Kerja Indonesia}

Tenaga Kerja Indonesia (TKI) adalah individu yang mampu bekerja dalam rangka menghasilkan jasa guna untuk memenuhi kebutuhan hidupnya. Kemudian dengan istilah Tenaga Kerja Indonesia (TKI) yang berasal dari istilah tenaga kerja, kemudian diberi tambahan belakang dengan kalimat Indonesia yang menunjukkan kata arti khusus yaitu Tenaga Kerja Indonesia. Namun istilah Tenaga Kerja Indonesia yang sering kita dengar dan yang dimaksud disini adalah Tenaga Kerja Indonesia yang mempunyai arti sendiri yaitu merupakan jabatan atau predikat seseorang yang dipekerjakan di luar negeri.

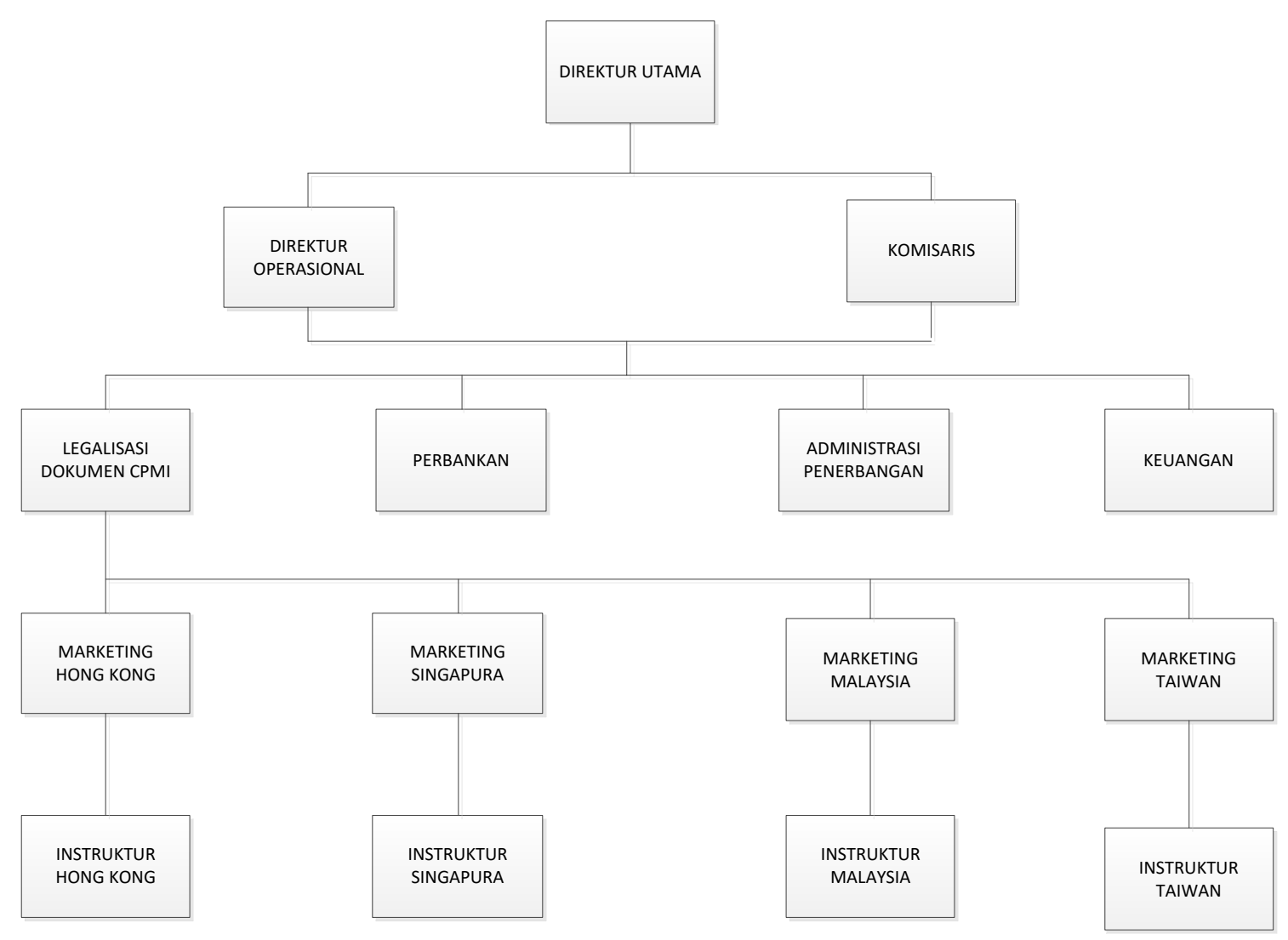

Gambar 1. Struktur Organisasi 


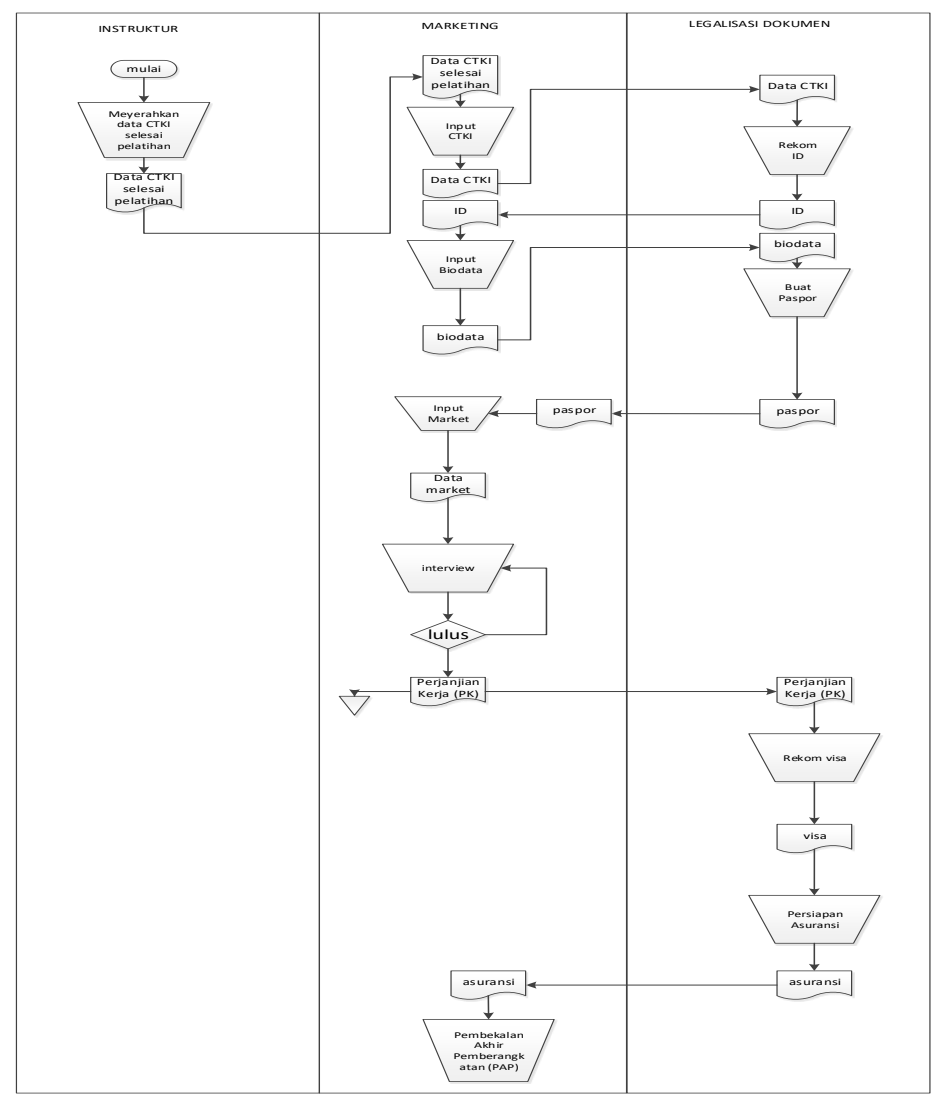

Gambar 2. Flow Map Manual Sistem Yang Berjalan

2.4. Analisa Sistem Ususlan

1. Flowmap

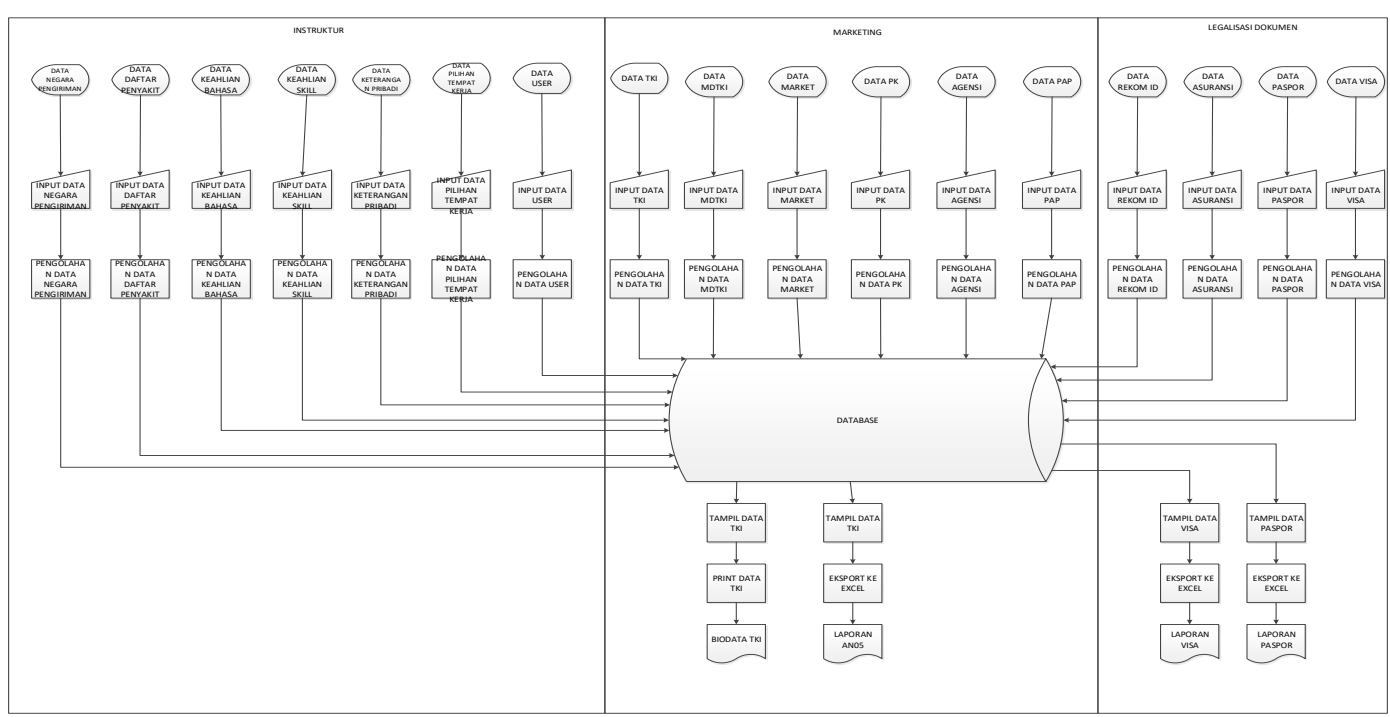

Gambar 3. Flow Map System Usulan 


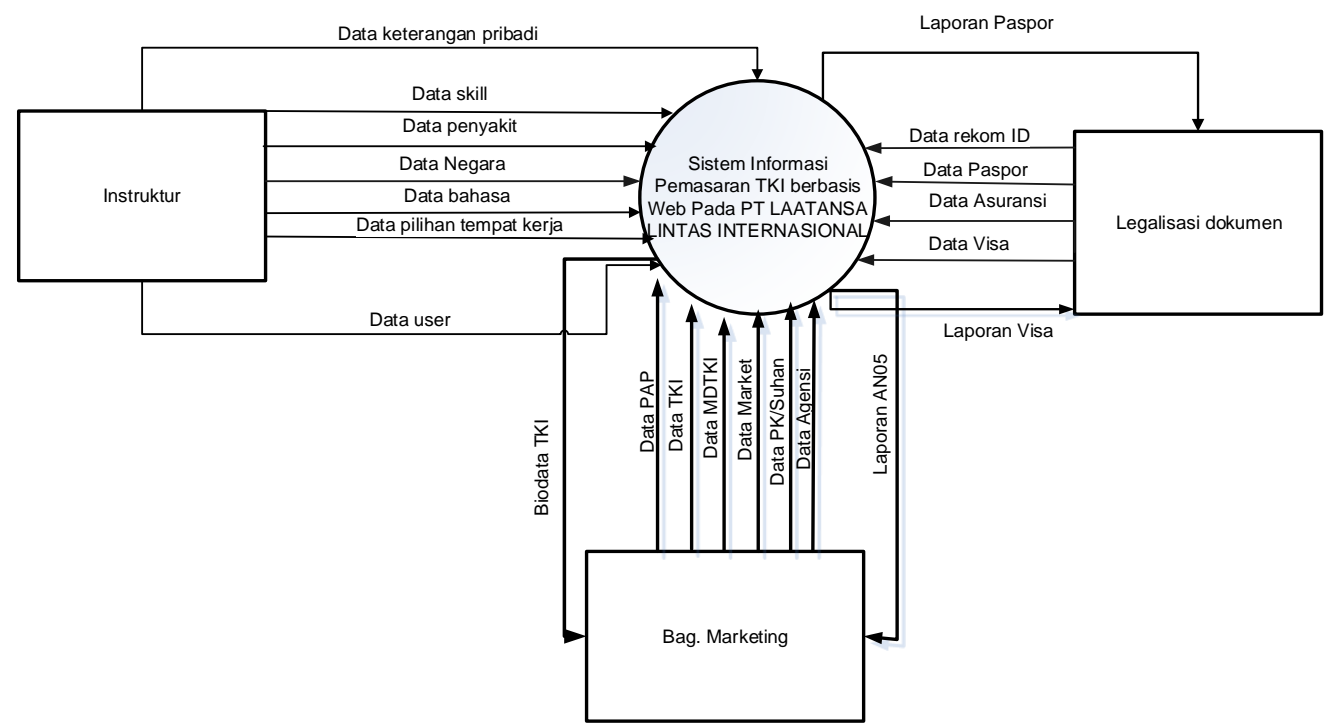

Gambar 4. Diagram Konteks Sistem Usulan

\section{Diagram Zero}

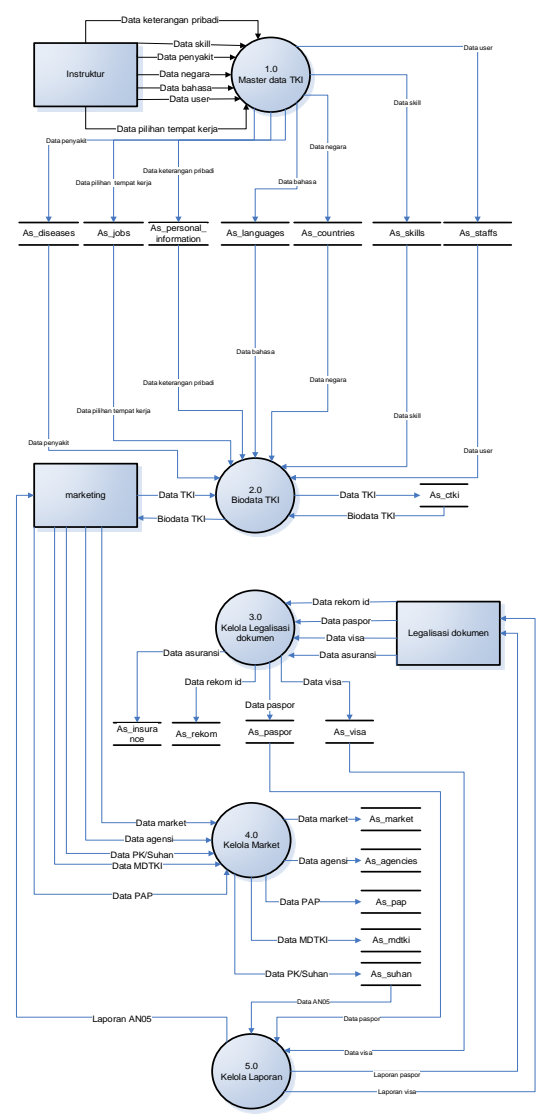

Gambar 5. Diagram Zero Sistem Usulan 


\section{Entity Relationship Diagram}

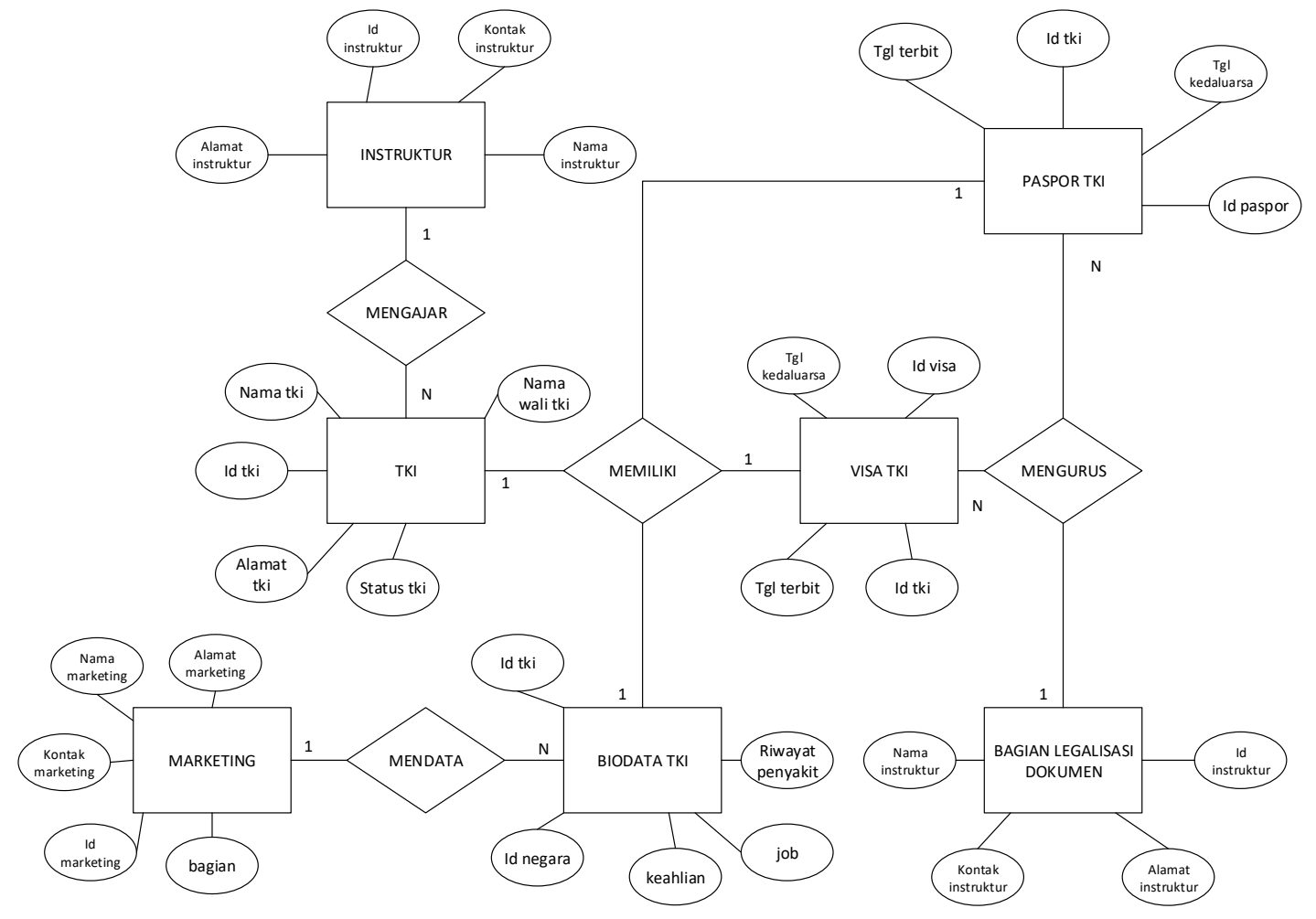

Gambar 6. Entity Relationship Diagram sistem usulan

\section{IMPLEMENTASI SISTEM}

Implementasi tampilan program adalah hasil dari perancangan tampilan program yang sebelumnya sudah dilakukan pada tahap perancangan sistem.

\subsection{Tampilan Form Login}

Form ini adalah tampilan awal ketika kita akan mengakses aplikasi. Pada form ini Marketing, Instruktur dan Bagian Legalisasi Dokumen harus memasukan username dan password agar bisa masuk ke halaman index masing-masing sesuai dengan hak akses dari aplikasi.

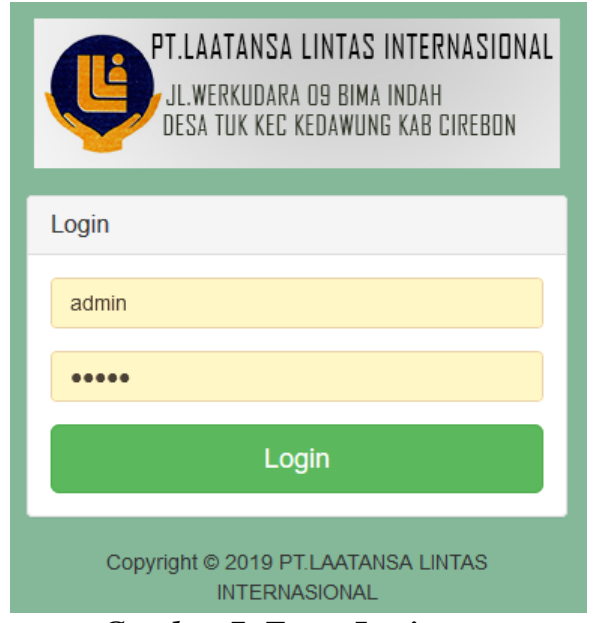

Gambar 7. Form Login 


\subsection{Form Master Data Negara Pengiriman}

Menu Master Data Negara Pengiriman berisi form untuk memasukkan daftar negara yang menjadi negara tujuan pengiriman Tenaga Kerja Indonesia di PT. Laatansa Lintas Internasional.

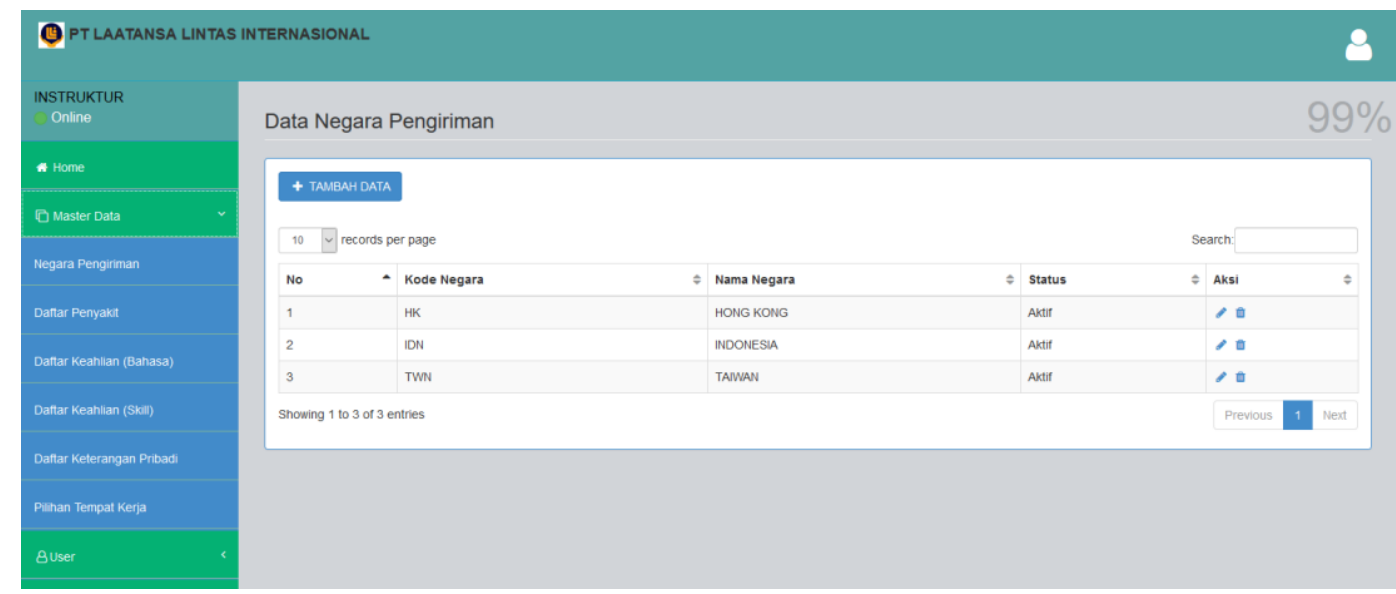

Gambar 8. Form Master Data Negara Pengiriman

\subsection{Form Input Biodata Tenaga Kerja Indonesia}

Form ini berfungsi untuk menginputkan biodata Tenaga Kerja Indonesia.

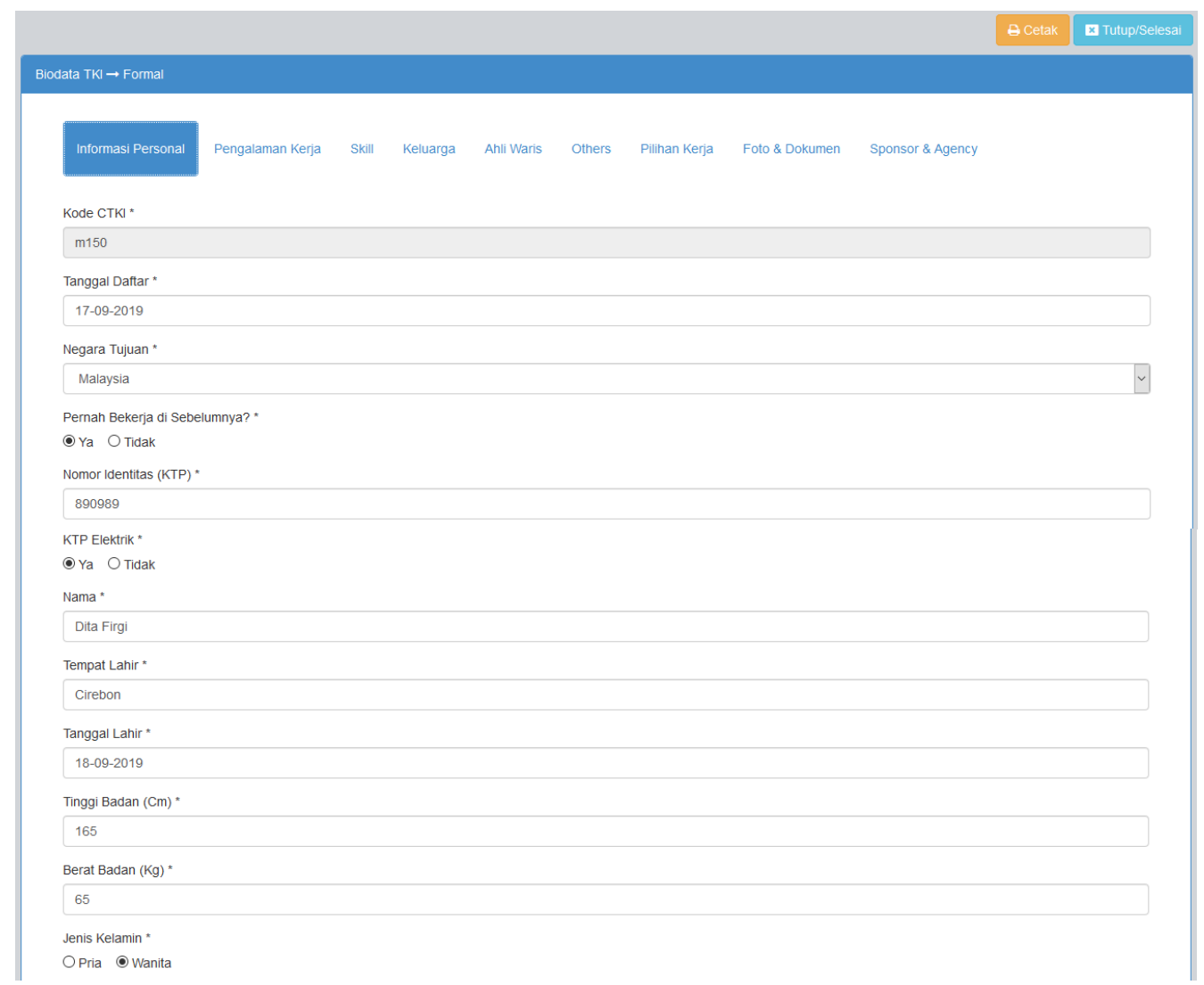




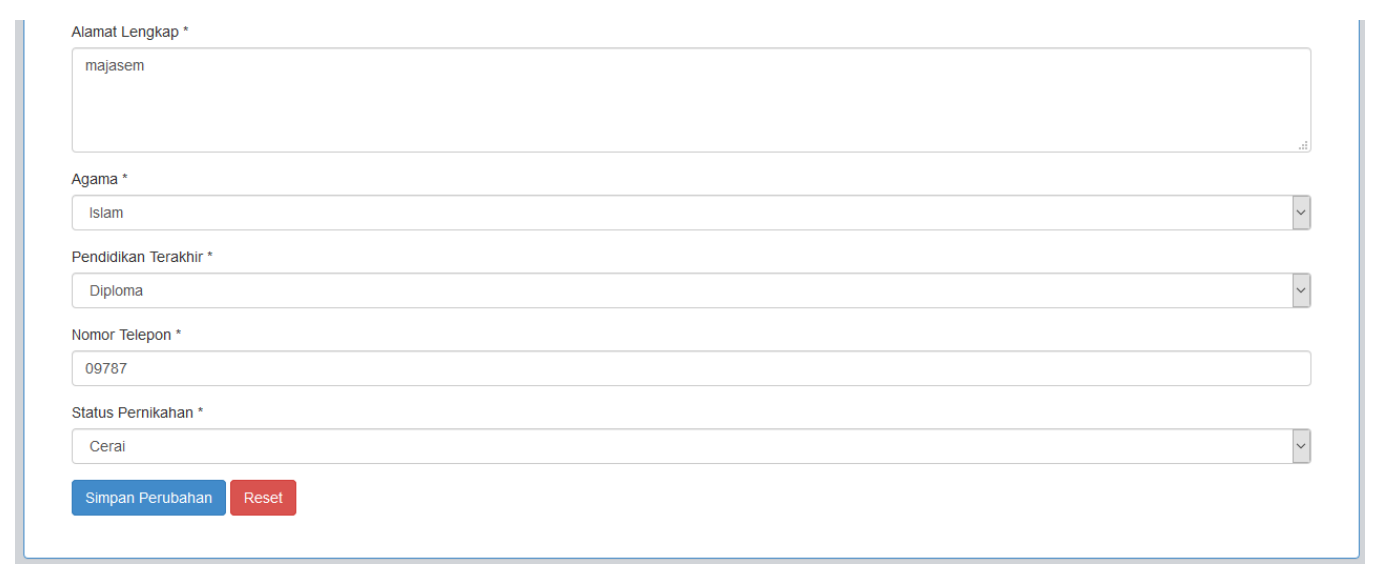

Gambar 9. Form Input Biodata Tenaga Kerja Indonesia

\section{KESIMPULAN DAN SARAN}

\subsection{Kesimpulan}

Berdasarkan hasil analisa dan perancangan, implementasi, serta pengujian dari sistem yang telah dibuat, maka penulis dapat membuat kesimpulan dalam penelitian ini sebagai berikut :

1. Sistem Informasi Pemasaran Tenaga Kerja Indonesia pada PT. Laatansa Lintas Internasional masih menggunakan sistem secara manual. Dengan dibuatnya perancangan Sistem Informasi Pemasaran secara komputerisasi mampu meningkatkan kualitas pelayanan pada PT. Laatansa Lintas Internasional secara lebih baik.

2. Sistem Informasi Pemasaran Tenaga Kerja Indonesia Pada PT. Laatansa Lintas Internasional dapat membantu bagian marketing untuk mempermudah proses pemasaran Tenaga kerja Indonesia ke luar negeri.

3. Aplikasi ini mampu mengefektipkan kinerja bagian legalisasi dokumen dalam pengarsipan data Tenaga Kerja Indonesia.

4. Aplikasi ini dirancang dengan menggunakan DFD sebagai tools perancangannya dan PHP sebagai Bahasa program yang digunakan serta $M y S Q L$ sebagai tempat penyimpanan data.

5. Aplikasi ini menghasilkan output berupa Biodata TKI, Laporan AN05, Laporan Passport dan Laporan Visa.

\subsection{Saran}

Adapun saran-saran untuk pengembangan sistem selanjutnya, penulis dapat memberikan saran-saran pengembangan sebagai berikut :

1. Diharapkan aplikasi ini dapat berintegrasi dengan bagian keuangan supaya mampu mengetahui laba rugi perusahan terkait dengan pemasaran Tenaga Kerja Indonesia yang sudah dilakukan di PT. Laatansa Lintas Internasional.

2. Untuk memperluas cakupan wilayah bisa ditambahkan data Lembaga Pelatihan Kerja sebagai data stok Tenaga Kerja Indonesia yang akan dipasarkan ke luar negeri.

3. Untuk perkembangan selanjutnya aplikasi ini diharapkan bisa dipakai tidak hanya di PT. Laatansa Lintas Internasional akan tetapi perusahaan-perusahaan jasa lain yang sejenis. 


\section{DAFTAR PUSTAKA}

[1] Anhar, 2010. PHP dan MySQL Secara Otodidak.PT. Trans Media. Jakarta

[2] A. Partato, Pius dan Al Barry, M. Dahlan, 2001. Kamus Ilmiah Populer. Surabaya: Arloka, 2001

[3] Arief M Rudianto. 2011. Pemrograman Web Dinamis menggunakan PHP. C.V ANDI OFFSET. Yogyakarta.

[4] Azhar, Susanto. 2009. Sistem Informasi Manajemen. Lingga Jaya. Bandung

[5] Daulay, Melwin Syahfrijal. 2007. Mengenal Hardware-Software dan Pengolahan Instalasi Komputer. Yogyakarta: Andi

[6] Depnaker, 1994. Pedoman Penempatan Kerja Ke Luar Negeri, Dirjen Pembinaan Penempatan Tenaga Kerja. Jakarta

[7] Depnaker RI, 1994. Peraturan Menteri Tenaga Kerja Tentang Penempatan Tenaga Kerja Ke Luar Negeri, Balai Akan. Jawa Timur

[8] Krismiaji, 2010. Sistem Informasi Akuntansi. Edisi Ketiga. Yogyakarta: Unit Penerbit Dan Percetakan Sekolah Tinggi Ilmu Manajemen YKPN.

[9] Kotler, Philip. 2001. Manajemen Pemasaran di Indonesia : Analisis, Perencanaan, Implementasi dan Pengendalian. Salemba Empat. Jakarta.

[10] Mamulang H, Sendjun, 1998. "Pokok-Pokok Hukum Ketenagakerjaan Di Indonesia". Jakarta. PT Rineka Citra.

[11] Rahardjo, Budi. 2015. Belajar Otodidak Pemrograman Web dengan PHP+Oracle, 1st ed. Bandung: INFORMATIKA.

[12] Subijanto, 2011. "Peran Negara Dalam Hubungan Tenaga Kerja Indonesia". Jurnal Pendidikan dan Kebudayaan.

[13] Sutarman, 2012. Buku Pengantar Teknologi Informasi. Jakarta. Andi Offset.

[14] Stanton, William J. 2001. Prinsip Pemasaran. Erlangga. Jakarta

[15] Swastha, Basu dan Irawan. 2005, Manajemen Pemasaran Modern, Liberty, Yogyakarta.

[16] Sutabri, Tata, 2012. Konsep Sistem Informasi. Yogyakarta: CV. Andi Offset.

[17] Taufiq, Rohmat, 2013. Sistem Informasi Manajemen. Yogyakarta: Graha Ilmu.

[18] Undang-Undang No 13 Tahun 2003 Tentang Tenaga Kerja

[19] Yakub, 2012. "Pengantar Sistem Informasi". Graha Ilmu: Yogyakarta. 